\title{
Prevalence and Impact of Subclinical Thyroid Dysfunction on Mortality among Patients Presenting with Cardiovascular Events
}

\author{
Paulette David Nacpil-Dominguez, ${ }^{1}$ Maria Luisa Rivera Arkoncel, ${ }^{1}$ \\ Gregory Joseph Ryan Ardeña, 1,2 Cecilia Jimeno ${ }^{1,3}$ \\ ${ }^{1}$ Section of Endocrinology, Diabetes, and Metabolism, Department of Medicine, University of the Philippines- Philippine General Hospital Manila \\ ${ }^{2}$ Panay Health Care MPC Hospital, Estancia, Kalibo, Aklan \\ ${ }^{3}$ Department of Pharmacology, College of Medicine, University of the Philippines Manila
}

\begin{abstract}
Objective. This study aims to determine the prevalence of subclinical thyroid dysfunction among cardiac patients at the Philippine General Hospital, and its association with mortality.

Methodology.163 adult cardiac patients were screened for subclinical thyroid dysfunction, [subclinical hyperthyroidism (SCT), subclinical hypothyroidism (SCHO), non-thyroidal illness syndrome (NTIS)]. Demographic and clinical characteristics were analyzed using ANOVA and Fisher's exact test. Outcome considered were hospital duration, need for mechanical ventilation, inotropic support and mortality. Crude association between subclinical thyroid dysfunction and outcomes was evaluated using relative risk.
\end{abstract}

Results. Prevalence of subclinical thyroid dysfunction was $32.5 \%$ (5.5\% SCT, 5.5\% SCHO, and $21.5 \%$ NTIS). The risk of necessitating mechanical ventilation was about twofold higher in subclinical thyroid dysfunction compared to euthyroid patients $(R R=2.64)$, and was highest in $\mathrm{SCHO}(\mathrm{RR}=3.71)$. The risk of inotropic support was about twofold higher $(\mathrm{RR}=2.70)$ in $\mathrm{SCHO}$ compared to euthyroid patients. Overall death rate was higher in subclinical thyroid dysfunction ( $R R=1.86)$, and highest in $\mathrm{SCHO}(\mathrm{RR}=2.47)$ compared to euthyroid patients.

Conclusion. There is a significant prevalence of subclinical thyroid dysfunction among hospitalized patients with cardiac disease at $32.5 \%$. Cardiovascular risk factors are not statistically significant. We observed a trend of increased risk of requiring mechanical ventilation, inotropes and overall mortality in $\mathrm{SCHO}$.

Key words: Subclinical thyroid dysfunction, prevalence, mortality

\section{INTRODUCTION}

The effects of overt hyper- or hypothyroidism on the cardiovascular system are well known, but whether subclinical or mild thyroid dysfunctions have clinical significance is still to be proven. A consensus conference on subclinical thyroid disease concluded that there is insufficient evidence whether subclinical thyroid dysfunction is associated with cardiovascular disease and increased mortality. ${ }^{1}$

Subclinical hyperthyroidism, defined as a low serum thyroid-stimulating hormone (TSH) concentration in an asymptomatic subject with normal serum triiodothyronine $\left(\mathrm{T}_{3}\right)$ and thyroxine $\left(\mathrm{T}_{4}\right)$ concentrations, is common in the community, with the prevalence reported to range from $0.5 \%$ to $3.9 \%$ in adults of all ages and $11.8 \%$ in a study among the elderly.2,3 On the other hand, subclinical hypothyroidism, defined as an elevated serum TSH level in the background of normal serum $\mathrm{T}_{3}$ and $\mathrm{T}_{4}$ values, affects around $4 \%$ of the general population and $10 \%$ to $15 \%$ of older persons. ${ }^{4}$

Non-thyroidal illness syndrome (NTIS) occurs during starvation or critical illness when thyroid hormones in blood are reduced to levels typical of hypothyroidism. Generally, serum T3 and free T3 are low, while serum T4 is likewise reduced in proportion to the severity and length of the illness. This is believed to be due to rapid inhibition of deiodination of $\mathrm{T} 4$ to $\mathrm{T} 3$ by type 1 iodothyronine deiodinase in the liver, causing the inhibition of T3 generation, as well as prevention of rT3 metabolism. One of the hallmarks of NTIS is a usually normal or inappropriately suppressed TSH, presumably due to reduced secretion from deficient TRH production. ${ }^{5}$

Relating thyroid dysfunction with deleterious cardiovascular effects is not without basis. Several mechanisms proposed include coronary vascular stenosis induced by local inflammation from autoimmune
e-ISSN 2308-118x

Printed in the Philippines

Copyright (C) 2014 by the JAFES

Received March 30, 2014. Accepted May 15, 2014.
Corresponding author: Paulette D. Nacpil-Dominguez, MD

Section of Endocrinology, Diabetes and Metabolism

University of the Philippines-Philippine General Hospital

Taft Avenue, Ermita

1000 Manila, Philippines

Tel. No.: +632-554-8400 local 3230

E-mail:paulettenacpil@yahoo.com 
thyroiditis, altered serum lipids, increased peripheral vascular resistance associated with subclinical hypothyroidism, and increased risk for atrial fibrillation and other cardiac dysrhythmias among patients with excess thyroid hormones. ${ }^{6-8}$ These changes translate to increased risk of coronary heart disease events and mortality in the future.

NTIS, low T3 syndrome or sick euthyroid syndrome is believed to be compensatory and is a beneficial response that decreases energy consumption in disease states. This alteration also has a negative prognostic impact, especially among patients with heart disease. ${ }^{9,10}$

At present, there is paucity of data regarding the prognostic impact of the disease in cardiac patients; and its association with mortality is controversial. One study which included 1026 acute cardiac patients had a $43 \%$ prevalence of subclinical thyroid dysfunction, the majority of whom had NTIS $(34.7 \%)$, the rest had subclinical hypothyroidism $(6.6 \%)$, and subclinical hyperthyroidism $(2.2 \%)$. The mortality rate was $22.15 \%$ and more than half of the deaths are due to cardiovascular causes. In-hospital mortality of the total population was $3.58 \% .^{11}$

This study was done to determine the institutional prevalence of subclinical thyroid dysfunction among patients with cardiovascular events and its impact on mortality. Recognizing the increased morbidity and fatal outcomes of cardiovascular events, this study will be able to provide additional data regarding recommendations in terms of screening "high risk" patients.

\section{METHODOLOGY}

\section{Design}

Cross-sectional, and Prospective Cohort Study

\section{Setting}

UP-Philippine General Hospital: The investigators identified potential eligible patients from the Emergency room (ER)-Acute Coronary Unit (ACU), Medical Intensive Care Units (MICU), and Medical Wards. Medical records were reviewed prior to blood extraction.

\section{Subjects}

The subjects included adult patients ( $>18$ years old) who presented with any of the following cardiovascular events at the acute care unit or the medical wards:

1. Acute coronary event (acute myocardial infarction, unstable angina)

ST-segment elevation myocardial infarction (STEMI) was confirmed by the presence of the following: 1) typical chest pain, 2) electrocardiographic findings of ST-segment elevation or $\mathrm{Q}$ waves, and 3) elevated myocardial enzymes. Unstable angina (UA) was defined as angina pectoris or equivalent ischemic discomfort with at least one of three features: 1) occurred at rest (or minimal exertion) usually lasting $>10$ minutes, 2) severe and of new onset (within the prior 4-6 weeks and/or 3) occurred with a crescendo pattern (i.e. distinctly more severe, prolonged, or frequent than previously). Non-ST-segment elevation myocardial infarction (NSTEMI) was established if a patient with the clinical features of UA developed evidence of myocardial necrosis, as reflected in elevated cardiac biomarkers.

2. Cardiac dysrhythmias [atrial fibrillation, complete atrioventricular (AV) block, sick sinus syndrome]

The presence of cardiac dysrhythmias on electrocardiography, such as atrial fibrillation, complete AV block, sick sinus syndrome, were reviewed and confirmed by a cardiology fellow for each case. A 24-hour Holter monitoring or other tests may be done to confirm the diagnosis.

\section{Congestive heart failure (CHF)}

The Framingham Criteria was used for the diagnosis of CHF. At least 1 Major and 2 Minor criteria were required to satisfy the diagnosis. The major criteria include paroxysmal nocturnal dyspnea, neck vein distention, rales, cardiomegaly, acute pulmonary edema, S3 gallop, increased venous pressure $(>16 \mathrm{~cm}$ $\mathrm{H} 20)$, positive hepatojugular reflux. Minor criteria include extremity edema, night cough, dyspnea on exertion, hepatomegaly, pleural effusion, vital capacity reduced by one-third from normal, and tachycardia $(>120 \mathrm{bpm})$. Weight loss $>4.5 \mathrm{~kg}$ over 5 days' treatment was considered either a major or minor criteria.

4. Pericardial diseases (pericarditis, pericardial effusion, cardiac tamponade)

Acute and chronic pericarditis was suspected in a patient with a history of pleuritic chest pain and fever, a physical finding of pericardial friction rub and an electrocardiographic finding of widespread STelevation with upward concavity. Pericardial effusion, on the other hand, was suspected in a dyspneic patient with muffled heart sounds and note of a patch of dullness beneath the angle of the left scapula (Ewart's sign). Characteristic electrographic findings include low-voltage QRS complexes and "electrical alternans." Confirmation of pericardial effusion or cardiac tamponade was made with note of presence of pericardial fluid as an echo-free space on twodimensional transthoracic echocardiography.

5. Hypertensive vascular diseases (malignant hypertension)

In addition to marked blood pressure elevation (usually diastolic BP $>130 \mathrm{~mm} \mathrm{Hg}$ ) in association with papilledema and retinal hemorrhages or 
exudates, malignant hypertension included manifestations of hypertensive encephalopathy such as severe headache, vomiting, transient paralysis, stupor and coma.

Confirmation of the cardiac diagnosis was verified by the actual assessment of the cardiology fellow for each case.

Before the blood extraction, the potential subjects understood and completed the Informed Consent, as explained thoroughly by the investigator before signing. The following baseline data were extracted: patient characteristics (age, sex), associated medical problems (hypertension, diabetes mellitus, dyslipidemia), and other significant cardiac risk factors (family history of sudden cardiac death, smoking).

\section{Exclusion Criteria}

All patients who have clinically apparent thyroid disease or already taking thyroid medications (levothyroxine, methimazole, carbimazole, thiamazole, propylthoiuracil and potassium iodide) were excluded from the study. Patients taking other medications that could potentially affect thyroid function testing were also excluded. These medications include: dopamine, levodopa, bromocriptine, glucocorticoids ( $>0.5 \mathrm{mg} /$ day dexamethasone, $100 \mathrm{mg} /$ day hydrocortisone), octreotide, amphetamines, metoclopramide, amiodarone, iodinated contrast media, furosemide ( $>80 \mathrm{mg} /$ day), nonsteroidal agents (salicylates $>2 \mathrm{gm} /$ day, salsalate $>1.5-3 \mathrm{gm} /$ day, diclofenac, naproxen), IV heparin, phenytoin, and carbamazepine. ${ }^{12}$ Pregnant patients were also excluded.

\section{Classification by Thyroid Status}

Patients were classified into 1 of the following 6 groups based on their thyroid function tests: ${ }^{1-5}$

1. Overt thyrotoxicosis was defined as a TSH concentration of less than $0.10 \mathrm{mU} / \mathrm{L}$ with an elevated free $\mathrm{T} 4$ or free $\mathrm{T} 3$

2. Subclinical hyperthyroidism (SCT) was defined as a $\mathrm{TSH}$ concentration of $0.10 \mathrm{mU} / \mathrm{L}$ to $0.24 \mathrm{mU} / \mathrm{L}$ or less than $0.10 \mathrm{mU} / \mathrm{L}$ with a normal free $\mathrm{T} 4$ or free $\mathrm{T} 3$

3. Euthyroidism (EU) was defined as a normal TSH concentration of $0.25 \mathrm{mU} / \mathrm{L}$ to $4.0 \mathrm{mU} / \mathrm{L}$ and normal free $\mathrm{T} 4$ and free $\mathrm{T} 3$

4. Subclinical hypothyroidism (SCHO) was defined as a TSH concentration of more than $4.0 \mathrm{mU} / \mathrm{L}$ or less than $10 \mathrm{mU} / \mathrm{L}$ with a normal free $\mathrm{T} 4$ or free $\mathrm{T} 3$ concentration

5. Overt hypothyroidism was defined as a TSH level of more than $10 \mathrm{mU} / \mathrm{L}$ or more than $5 \mathrm{mU} / \mathrm{L}$ with a free $\mathrm{T} 4$ or free $\mathrm{T} 3$ concentration below normal
6. Nonthyroidal illness syndrome (NTIS) was defined as low or normal TSH with a low free T4 or low free T3

\section{Study Outcomes}

Subjects were followed up until the day of discharge. The outcomes of measure include: hospital duration, need for mechanical ventilation and inotropic support, and allcause mortality.

\section{Hormonal Measurements}

Serum free $T_{4}$ and $T_{3}$, and TSH concentrations were determined from blood samples drawn immediately after arrival in the emergency department and prior to any intravenous therapy, including administration of heparin. Ascertainment of serum free $\mathrm{T}_{3}$ and $\mathrm{T}_{4}$ were accomplished using enzyme immunoassays while TSH utilized the IRMA method. We used study specific cut off values (Manila Endocrine Laboratory) as follows: free $\mathrm{T}_{4}$ (11.5$23.0 \mathrm{pmol} / \mathrm{L})$, free $\mathrm{T}_{3}(2.5-5.0 \mathrm{pmol} / \mathrm{L})$, and TSH $(0.25-4.0$ $\mathrm{mIU} / \mathrm{ml}$ )

\section{Statistical Analysis}

The sample size that is required to estimate the prevalence of subclinical thyroid dysfunction is 163, given an estimated prevalence of $12 \%$ with $5 \%$ error given a $95 \%$ confidence interval. ${ }^{13,14}$ Of the 163 patients included in the study, 142 were analyzed. Demographic and clinical characteristics were analyzed as subclinical thyroid dysfunction group (SCT, SCHO and NTIS), and then each subgroup. The crude association between subclinical thyroid dysfunction and outcomes was evaluated using relative risk

\section{RESULTS AND DISCUSSION}

The overall prevalence of subclinical thyroid dysfunction among patients with cardiovascular events was $32.5 \%$ (53/163), and more than half of the cases have NTIS. (Table 1). There are few reports on the prevalence of the disease among cardiac patients, with varying selective criteria. A study from Italy showed a prevalence rate of $43.6 \%$, and the most frequent subclinical thyroid dysfunction was NTIS at $34.7 \%$. The prevalence of SCHO closely paralleled that of our study $(6.6 \%$ vs $5.5 \%) .{ }^{11}$ At present, there is no local published data available for comparison, however, our study further supports previous findings of high prevalence of the clinical condition as seen in international studies.

In a national survey of thyroid dysfunction in the country, the prevalence was $8.53 \%$ in the general population, with the predominant problems being SCT and SCHO. ${ }^{15}$ This value appears low, probably because NTIS was not determined in the study, and the majority of participants were middle-aged. The prevalence of SCT in our study 
was comparable with that of the general population $(5.5 \%$ vs. $5.33 \%) .{ }^{15}$ However, it is difficult to compare our findings because of the difference in populations studied.

Knowing the consequences of even mildly altered thyroid hormone status, this study may help clinicians decide whether screening for subclinical thyroid dysfunction is warranted, especially in those with cardiovascular events.

\begin{tabular}{|c|c|c|}
\hline Thyroid Function Status & Frequency & Percent (\%) \\
\hline Euthyroidism & 89 & 54.6 \\
\hline Subclinical hyperthyroidism & 9 & 5.5 \\
\hline Subclinical hypothyroidism & 9 & 5.5 \\
\hline Overt thyrotoxicosis & 3 & 1.8 \\
\hline Overt hypothyroidism & 7 & 4.3 \\
\hline Nonthyroidal Illness & 35 & 21.5 \\
\hline Unclassified & 11 & 6.7 \\
\hline Total & 163 & 100 \\
\hline
\end{tabular}

The study population was composed mainly of older patients, with about $45 \%$ of the sample population aged 60 and above. Males comprised $44.78 \%$ of the total population (Table 2.1). Patients with SCT tend to be older (Table 2.2), however, this was not statistically significant. Both SCT and SCHO are known to be more common among women and elderly. ${ }^{4,16-19}$ SCT has been particularly well studied among the elderly population. It is associated with a higher mortality rate in chronically ill geriatric patients $(62 \%$ versus $28 \%, \mathrm{p}<0.05)$ and poses a 2.2 -fold risk in mortality from all causes and 3 -fold in cardiovascular among those aged $>60$ years old after a single measurement of low TSH. ${ }^{19}$ These studies provide evidence for the recommendation on the screening for thyroid dysfunction and treatment of subclinical hyperthyroidism among the elderly. ${ }^{20,21}$

Cardiovascular risk factors and comorbidities did not statistically differ between euthyroid and subclinical thyroid dysfunction, except for family history of early cardiac death and probably smoking history. (Table 2.1). When further analyzed, this was not found significant in any of the subgroups. On the other hand, history of malignancy was significant, however, the numbers were too small (Table 2.2).

Diabetes is one of the clinical conditions associated with thyroid dysfunction. This has been recognized since 1979, with subclinical hypothyroidism being the most common. ${ }^{22-25}$ Thyroid hormones have a direct action in insulin secretion. In hypothyroidism, there is a reduction in glucose-induced insulin secretion by beta cells, while the response of beta cells to glucose or catecholamine is increased in hyperthyroidism due to increased beta cell mass. Moreover, insulin clearance is increased in thyrotoxicosis. ${ }^{26,27}$ SCT in type 2 diabetic patients tend to increase with age and among women, and is associated with an increase cardiovascular disease and mortality. ${ }^{25}$

\begin{tabular}{|c|c|c|c|}
\hline & $\begin{array}{c}\text { Euthyroid } \\
\quad(n=89)\end{array}$ & $\begin{array}{c}\text { Subclinical } \\
\text { dysfunction } \\
(n=53)\end{array}$ & p-value \\
\hline Age in years, Mean (SD) & $56.9(12.7)$ & $57.4(12.4)$ & 0.85 \\
\hline Male Sex, $n(\%)$ & $45(50.6)$ & $26(50.9)$ & 1.000 \\
\hline Hypertension (n, \%) & $58(65.2)$ & 36 967.9) & 0.855 \\
\hline Diabetes mellitus ( $\mathrm{n}, \%$ ) & $21(23.6)$ & $18(34.0)$ & 0.243 \\
\hline Dyslipidemia $\quad(n, \%)$ & $7(7.9)$ & $6(11.3)$ & 0.553 \\
\hline Family history early cardiac death $(n, \%)$ & $7(7.9)$ & 0 & 0.046 \\
\hline Smoking history $(\mathrm{n}, \%)$ & $47(52.8)$ & $19(35.8)$ & 0.057 \\
\hline Bronchial Asthma (n, \%) & $6(6.7)$ & $1(1.9)$ & 0.257 \\
\hline Pulmonary tuberculosis $(\mathrm{n}, \%)$ & $10(11.2)$ & $8(15.1)$ & 0.604 \\
\hline Kidney disease $(n, \%)$ & $7(7.9)$ & $5(9.5)$ & 0.762 \\
\hline Liver disease $(n, \%)$ & $2(2.3)$ & 0 & 0.529 \\
\hline Cerebrovascular disease $(n, \%)$ & $11(12.4)$ & $3(5.7)$ & 0.252 \\
\hline Malignancy $(\mathrm{n}, \%)$ & $2(2.3)$ & $2(3.8)$ & 0.629 \\
\hline
\end{tabular}

In terms of the cardiovascular events, acute myocardial infarction and heart failure comprised more than $50 \%$ of the cardiac diagnosis, similar to that seen in the population studied by Molinaro. ${ }^{11}$ Dysrhythmia was statistically different between the two groups, but no difference was found when further analyzed across the subgroups (Table 3.1 and 3.2).

A low serum TSH concentration is generally a sensitive marker of thyroid hormone excess and has been reported in a large population-based study to be associated with a 3-fold higher risk of developing atrial fibrillation (AF) in the subsequent decade..$^{28}$ The cumulative incidence of $\mathrm{AF}$ after 10 years among subjects with a low TSH concentration ( $\leq 0.1 \mathrm{mU} / \mathrm{liter})$ was $28 \%$, compared with $11 \%$ in those with a normal TSH $(\mathrm{p}=0.005)$. The presence of atrial fibrillation predisposes to embolic events, which may contribute to increased vascular mortality among patients with excess thyroid hormones.

\begin{tabular}{|c|c|c|c|c|c|}
\hline & $\begin{array}{c}\text { Euthyroid } \\
(n=89)\end{array}$ & $\begin{array}{c}\text { Subclinical } \\
\text { hyperthyroidism }(n=9)\end{array}$ & $\begin{array}{c}\text { Subclinical } \\
\text { hypothyroidism }(n=9)\end{array}$ & $\begin{array}{c}\text { NTIS } \\
(n=35)\end{array}$ & $p$-value ${ }^{a}$ \\
\hline Age in years, Mean (SD) & $56.9(12.7)$ & $66.9(6.6)$ & $54.2(15.2)$ & $55.7(11.8)$ & 0.093 \\
\hline Male Sex, $n(\%)$ & $45(50.6)$ & $5(55.6)$ & $6(66.7)$ & $16(45.7)$ & 0.753 \\
\hline Hypertension (n, \%) & $58(65.2)$ & $8(88.9)$ & $6(66.7)$ & $22(62.9)$ & 0.573 \\
\hline Diabetes mellitus ( $\mathrm{n}, \%)$ & $21(23.6)$ & $5(55.6)$ & $3(33.3)$ & $10(28.6)$ & 0.224 \\
\hline Dyslipidemia $\quad(n, \%)$ & $7(7.9)$ & $2(22.2)$ & $1(11.1)$ & $3(8.6)$ & 0.433 \\
\hline Family history early cardiac death (n, \%) & $7(7.9)$ & 0 & 0 & 0 & 0.395 \\
\hline Smoking history $(n, \%)$ & $47(52.8)$ & $4(44.4)$ & $2(22.2)$ & $13(37.1)$ & 0.187 \\
\hline Bronchial Asthma (n, \%) & $6(6.7)$ & 0 & 0 & $1(2.9)$ & 0.876 \\
\hline Pulmonary tuberculosis $(\mathrm{n}, \%)$ & $10(11.2)$ & 0 & $3(33.3)$ & $5(14.3)$ & 0.189 \\
\hline Kidney disease $(n, \%)$ & $7(7.9)$ & 0 & 0 & $5(14.3)$ & 0.517 \\
\hline Liver disease $(n, \%)$ & $2(2.3)$ & 0 & 0 & 0 & 1.000 \\
\hline Cerebrovascular disease $(n, \%)$ & $11(12.4)$ & 0 & $1(11.1)$ & $2(5.7)$ & 0.600 \\
\hline Malignancy $(n, \%)$ & $2(2.3)$ & 0 & $2(22.2)$ & 0 & 0.054 \\
\hline
\end{tabular}


Several studies have demonstrated altered thyroid hormone metabolism, particularly low FT4 or FT3, among cardiac patients (i.e., myocardial infarction, heart failure), and is suggested to be an independent predictor of mortality. ${ }^{10,29,30}$ Serum T4 below $4 \mathrm{pmol} / \mathrm{L}$ is associated with a marked increased risk of death, while a serum T4 below $2 \mathrm{pmol} / \mathrm{L}$ denotes an extremely guarded prognosis. On the other hand, increased levels of reverse T3 during admission after a myocardial infarction, is found to be associated with subsequent short-term and long-term mortality, independent of risk factors. ${ }^{30}$

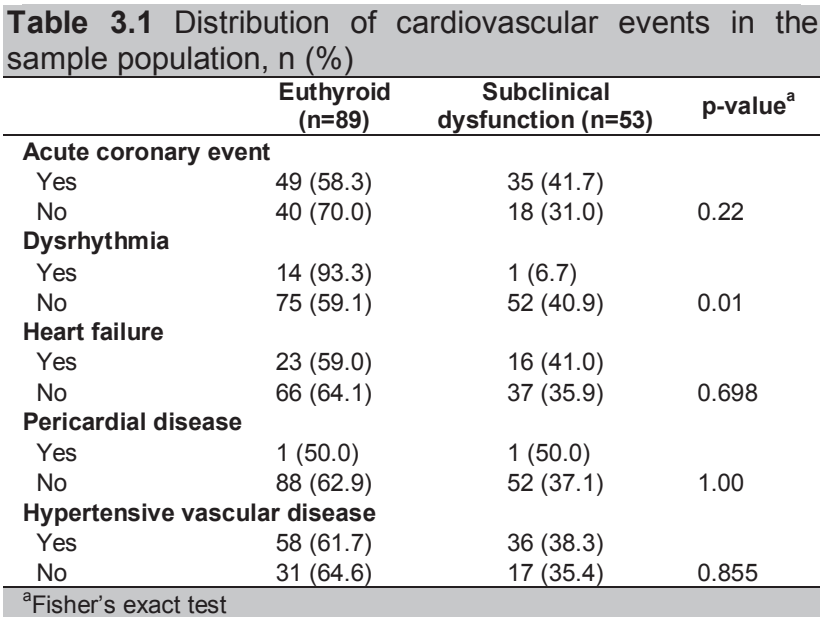

Studies on subclinical hypothyroidism and cardiovascular disease have conflicting results. In cohort studies from the United Kingdom, there was no increase in cardiovascular risk among subjects with subclinical hypothyroidism. In contrast, the Rotterdam Study reported an increased prevalence of myocardial infarction among women 55 years or older with subclinical hypothyroidism. ${ }^{31}$ In the longitudinal analysis of subjects with subclinical hypothyroidism, there were 21 cardiovascular deaths observed compared with 9.5 expected (age- and sexadjusted hazard ratio, 1.5; 95\% confidence interval, 1.0-2.4; $\mathrm{p}=.08$ ) and 33 coronary heart disease events observed compared with 14.7 expected (age- and sex adjusted hazard ratio, 1.7; 95\% confidence interval, 1.2- 2.4; p.=01). The increased risk of coronary heart disease events remained significant after further adjustment for standard cardiovascular risk factors. ${ }^{13}$
The risk of requiring the use of mechanical ventilation was higher among patients with subclinical thyroid dysfunction $(R R=2.64)$ compared to euthyroid patients. The risk was highest in SCHO compared to euthyroid patients $(\mathrm{RR}=3.71)$. Likewise, the risk of inotropic support was highest $(\mathrm{RR}=2.70)$ in $\mathrm{SCHO}$ compared to euthyroid patients. Prolonged hospital duration ${ }^{32}$ did not differ between the two groups. (Table 4.1 and 4.2). Overt hypothyroidism and its milder forms, SCHO and NTIS, result in depressed ventilatory control. ${ }^{33}$ Persistent, critically ill patients, often develop muscle dysfunction that is probably due to decreased mitochondrial activity and content. ${ }^{34}$ Since thyroid hormones are involved in mitochondrial function and biogenesis, the changes may be relevant to the pathogenesis of respiratory failure..$^{35}$ However, whether this study finding is caused solely by the presence of the thyroid dysfunction, or due to other confounding factors such as comorbidities, sepsis etc., cannot be dismissed.

In terms of in-hospital mortality, 9/52 (17.3\%) with subclinical thyroid dysfunction died, compared to $8 / 87$ (9.2\%) euthyroid patients. The patient with SCT and 2 with SCHO died of cardiac causes. Among those with NTIS, cardiovascular deaths accounted for 4 patients and non-cardiac deaths for 2 patients. The risk of dying among patients with subclinical thyroid dysfunction as opposed to those who were euthyroid was about twice as high $(\mathrm{RR}=1.86)$. The risk was highest among SCHO patients ( $R R=2.47)$ (Table 4.1 and 4.2).

In one study, the overall death rate was $12.75 \%$. However, the investigators excluded patients with acute coronary event, pulmonary edema and mainly categorized subjects to have ischemic and non-ischemic heart disease. ${ }^{36}$ In another study, which closely resembled our present study in selection criteria and outcomes considered, the overall death rate was $22.15 \%$, mainly because there was longer follow up with patients after the hospital admission. Hazard ratios for both cardiac and overall deaths was significantly higher in all patients with subclinical thyroid dysfunction compared to euthyroid patients (1.937, $\mathrm{p}=0.018 ; 1.933, \mathrm{p}=0.012) .{ }^{11}$ And consistently, more than half of the patients in each study died of a cardiac cause.

\begin{tabular}{|c|c|c|c|c|c|}
\hline & $\begin{array}{c}\text { Euthyroid } \\
(n=89)\end{array}$ & $\begin{array}{c}\text { Subclinical } \\
\text { hyperthyroidism }(n=9)\end{array}$ & $\begin{array}{c}\text { Subclinical } \\
\text { hypothyroidism }(n=9)\end{array}$ & $\begin{array}{c}\text { NTIS } \\
(n=35)\end{array}$ & $p$-value ${ }^{a}$ \\
\hline \multicolumn{6}{|c|}{ Acute coronary event } \\
\hline Yes & $49(58.3)$ & $8(9.5)$ & $5(6.0)$ & $22(26.2)$ & \\
\hline No & $40(69.0)$ & $1(1.7)$ & $4(6.9)$ & $13(22.4)$ & 0.243 \\
\hline \multicolumn{6}{|c|}{ Dysrhythmia } \\
\hline Yes & $14(93.3)$ & 0 & 0 & $1(6.7)$ & \\
\hline No & $75(59.1)$ & $9(7.1)$ & $9(7.1)$ & $34(26.8)$ & 0.10 \\
\hline \multicolumn{6}{|c|}{ Heart failure } \\
\hline Yes & $23(59.0)$ & $1(2.6)$ & $3(7.7)$ & $12(30.8)$ & \\
\hline No & $66(64.1)$ & $8(7.8)$ & $6(5.8)$ & $23(22.3)$ & 0.51 \\
\hline \multicolumn{6}{|c|}{ Pericardial disease } \\
\hline Yes & $1(50.0)$ & 0 & $1(50.0)$ & 0 & \\
\hline No & $88(62.9)$ & $9(6.4)$ & $8(5.7)$ & $35(25.0)$ & 0.298 \\
\hline \multicolumn{6}{|c|}{ Hypertensive vascular disease } \\
\hline Yes & $58(61.7)$ & $8(8.5)$ & $3(6.2)$ & $22(23.4)$ & \\
\hline No & $31(64.6)$ & $1(2.1)$ & $6(6.4)$ & $13(27.1)$ & 0.573 \\
\hline
\end{tabular}


Table 4.1 Outcomes in the sample population, $n(\%)$

\begin{tabular}{lccc}
\hline & $\begin{array}{c}\text { Euthyroid } \\
(\mathbf{n}=\mathbf{8 9})\end{array}$ & $\begin{array}{c}\text { Subclinical } \\
\text { dysfunction }(\mathbf{n}=\mathbf{5 3 )}\end{array}$ & $\begin{array}{c}\mathbf{R R} \\
\mathbf{( 9 5 \% ~ C l )}\end{array}$ \\
\hline Mortality & $8(9.0)$ & $9(17.0)$ & $1.86(0.81,4.32)$ \\
Mechanical Ventilation & $8(9.0)$ & $14(26.4)$ & $2.64(1.29,5.42)$ \\
Inotropes & $11(12.4)$ & $10(18.9)$ & $1.29(0.63,2.66)$ \\
Hospital duration & $28(31.5)$ & $14(26.4)$ & $0.91(0.53,1.55)$ \\
\hline${ }^{*}$ Prolonged hospital stay defined as $\geq 7$ days & &
\end{tabular}

Table 4.2 Outcomes in the sample population, $n(\%)$

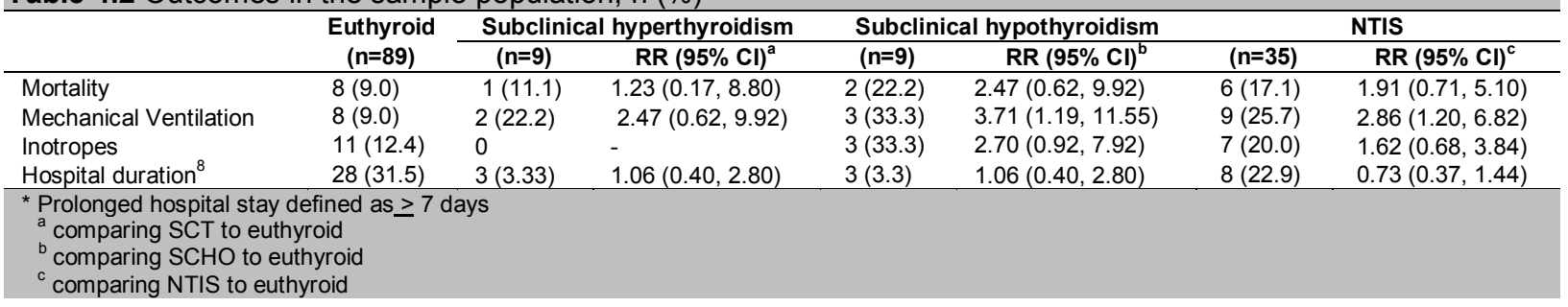

Different studies have shown that any form of subclinical thyroid dysfunction has a negative prognostic impact among cardiac patients. ${ }^{10,11,29,30,36}$ Although the present results cannot make any significant association between subclinical thyroid dysfunction and adverse clinical outcomes due to our limited sample size, there is a trend towards increased mortality. It is also noteworthy to mention the higher risk in terms of the outcomes (mechanical ventilation, inotrope use and mortality) in the $\mathrm{SCHO}$ group. This is an area for further research.

\section{Limitations of the Study}

The study only tested thyroid function once, upon evaluation, and cannot account for transient cases of subclinical dysfunction. Ideally, another test, taken 6-8 weeks from admission should have been taken. Also, additional testing to define the nature of the thyroid disease (i.e., ultrasonography, thyroid scintigraphy, antibody determination) should have been done. And because this is an observational study, even after adjusting for multiple variables, the possibility of residual confounding remains.

\section{CONCLUSION}

There is a high prevalence of subclinical thyroid dysfunction among patients with cardiovascular events at $32.5 \%$, majority have nonthyroidal illness. The difference in cardiovascular risk factors was not statistically significant. The need for mechanical ventilation and inotropic support were highest in SCHO ( $R R=3.71$. 2.70, respectively) compared to euthyroid. A trend towards increased mortality among patients with subclinical thyroid dysfunction was found ( $R R=1.86)$, and the risk was highest in SCHO (RR=2.47) compared to euthyroid.

\section{Acknowledgments}

This study is a recipient of the Philippine Society of Endocrinology and Metabolism Research Grant in 2008. The authors are also grateful for the invaluable contributions from the
Department of Emergency Medicine, Department of Internal Medicine, Section of Cardiology, of the University of the Philippines-Philippine General Hospital and Mrs. Rhodora Montemayor.

\section{References}

1. Surks MI, Ortiz E, Daniels GH. Subclinical thyroid disease: Scientific review and guidelines for diagnosis and management. JAMA. 2004; 291:228-238.

2. Bagchi N, Brown T, Parish R. Thyroid dysfunction in adults over age 55 years. A study in an urban US community. Arch Intern Med. 1990; 150:785-787.

3. Parle J, Franklyn J, Cross K, Jones C. Prevalence and follow-up of abnormal thyrotropin concentrations in the elderly in the United Kingdom. Clin Endocrinol. 1991; 34:77-83.

4. Hollowell JG, Staehling NW, Flanders WD, Hannon Wh, Gunter Ew, Spencer Ca et al. Serum TSH, T4, and thyroid antibodies in the United States population (1988 to 1994): National Health and Nutrition Examination Survey (NHANES III). J Clin Endocrinol Metab. 2002; 87:489-499.

5. De Groot LJ. Dangerous dogmas in medicine: The nonthyroidal illness syndrome. JCEM. 1999; 84(1):151-164.

6. Singh S, Duggal J, Molnar J, Maldonado F, Barsano CP, Arora R. Impact of subclinical thyroid disorders on coronary heart disease, cardiovascular and all-cause mortality: A meta-analysis. Int J Cardiol. 2008 Mar 28; 125(1):41-8. (p.4)

7. Osman F, Gammage MD, Sheppard MC, Franklyn JA. Cardiac dysrhythmias and thyroid dysfunctions - the hidden menace? J Clin Endocrinol Metab 2002; 87(3):963-967.

8. Biondi B, Palmieri EA, Lombardi G, Fazio S. Effects of subclinical thyroid dysfunction on the heart. Ann Intern Med. 2002; 137:904-914

9. Utiger RD. Altered thyroid function in nonthyroidal illness and surgery: To treat or not to treat? N Engl J Med. 1995; 333:1562-1563.

10. Iervasi G, Pingitor A, Landi P, Raciti M, Ripoli A, Scarlattini M et al. Low-T3 Syndrome a strong prognostic predictor of death in patients with heart disease. Circulation. 2003; 107:708-713.

11. Molinaro S, Iervasi G, Lorenzoni V, Coceani M, Landi P, Srebot V et al. Persistence of mortality risk in patients with acute cardiac diseases and mild thyroid dysfunction. Am J Med Sci. 2012; 343(1):65-70.

12. Dong BJ. How medications affect thyroid function. West J Med. 2000; 172:102-106.

13. Walsh JP, Bremner AP, Bulsara MK, O'Leary P, Leedman P, Feddema $\mathrm{P}$, Michelangeli V. Subclinical thyroid dysfunction as a risk factor for cardiovascular disease. Arch Intern Med. 2005; 165: 2467-2472.

14. Rodondi N, Newman AB, Vittinghoff E, de Rekeneire N, Satterfield S, Harris T, Bauer DC. Subclinical hypothyroidism and the risk of heart failure, other cardiovascular events, and death. Arch Intern Med. 2005; 165:2460-2466.

15. Carlos-Raboca J, Jimeno CA, Kho SA, Andag-Silva AA, Jasul Jr. GV, Nicodemus, Jr. NA et al. The Philippine Thyroid Diseases Study (PhilTiDeS 1): Prevalence of thyroid disorders among adults in the Philippines. JAFES. 2012; 27 (1):27-33. 
16. Cooper DS. Clinical practice. Subclinical hypothyroidism. N Engl J Med. 2001; 345:260 -265.

17. Canaris GJ, Manowitz NR, Mayor G, Ridgway EC. The Colorado thyroid disease prevalence study. Arch Intern Med. 200; 160:526-534.

18. Toft AD. Clinical practice. Subclinical hyperthyroidism. N Engl J Med 2001; 45:512-516.)

19. Parle JV, Maisonneuve P, Sheppard MC, Boyle P, Franklyn JA. Prediction of all-cause and cardiovascular mortality in elderly people from one low serum thyrotropin result: A 10-year cohort study. Lancet. 2001; 358:861-865. (p.10)

20. Volzke H, Schwahn C, Wallaschofski H, Dorr M. The relation of thyroid dysfunction with all-cause and circulatory mortality: Is there a causal relationship? J Clin Endocrinol Metab, 2007; 92: 2421-2429. (p.11)

21. Kovacs G. Subclinical hyperthyroidism and mortality rate in geriatric patients. The thyroid and cardiovascular risk: Merck European Thyroid Symposium Berlin 2004, June 10-13.

22. Papazafiropoulou A, Sotiropoulos A, Kokoloki A, Kardara M, Stamataki P, Pappas S: Prevalence of thyroid dysfunction among Greek type 2 diabetic patients attending an outpatient clinic. J Clin Med Res. 2010; 2:75-78.

23. Sathyapalan T, Manuchehri AM, Rigby AS, Atkin SL. Subclinical hypothyroidism is associated with reduced all-cause mortality in patients with type 2 diabetes. Diabetes Care. 2010; 33(3):E37.

24. Palma CCSSV, Paves M, Nogueira VG, Clemente ELS, Vasconcellos MDFBMP, Pereira Jr LC. Prevalence of thyroid dysfunction in patients with diabetes mellitus. Diabetology \& Metabolic Syndrome. 2013; 5:58.

25. Díez JJ1, Iglesias P. Subclinical hyperthyroidism in patients with type 2 diabetes. Endocrine. 2012; 42(1):157-63.

26. Stanicka ' $\mathrm{S}$, VondraK, Pelika 'nova' $\mathrm{T}$, Hill PVM, Zamrazil V. Insulin sensitivity and counter-regulatory hormones in hypothyroidism and during thyroid hormone replacement therapy. Clinical Chemistry and Laboratory Medicine. 2005; 43(7):715-720.
27. Mitrou P, Raptis SA, Dimitriadis G. Insulin action in hyperthyroidism: A focus on muscle and adipose tissue. Endocrine Reviews. 2010; 31(5): 663-679.

28. Sawin CT, Séller A, Wolf PA, Belanger AJ, Baker E, Bacharach P, et al Low serum thyrotropin concentrations as a risk factor for atrial fibrillation in older persons. NEJM 1994; 331(19): 1249-1252.

29. Hamilton MA, Stevenson LW, Luu M, Walden JA. Altered thyroid hormone metabolism in advanced heart failure. J Am Coll Cardiol. 1990; 16(1):91-95.

30. Friberg L, Drvota V, Bjelak AH, Eggertsen G, Ahnve S. Association between increased levels of reverse triiodothyronine and mortality after acute myocardial infarction. Am J Med. 2001;111:699 -703.

31. Hak AE, Pols HA, Visser TJ, Drexhage HA, Hofman A, Witteman JC. Subclinical hypothyroidism is an independent risk factor for atherosclerosis and myocardial infarction in elderly women: the Rotterdam Study. Ann Intern Med. 2000; 132: 270-278.

32. Wright SP, Verouhis D, Gamble G, Swedberg K, Sharpe N, Doughty RN. Factors influencing the length of hospital stay of patients with heart failure. Eur J Heart Fail (2003) 5 (2): 201-209.

33. Schlenker EH. Effects of hypothyroidism on the respiratory system and control of breathing: Human studies and animal models. Respir Physiol Neurobiol. 2012; 181(2):123-3.

34. Vanhorebeek I, De Vos R, Mesotten D, Wouters PJ, De Wolf-Peeters C, Van den Berghe G. Protection of hepatocyte mitochondrial ultrastructure and function by strict blood glucose control with insulin in critically ill patients. Lancet. 2005; 365:53-59.

35. Boelen A1, Kwakkel J, Fliers E. Beyond low plasma T3: Local thyroid hormone metabolism during inflammation and infection. Endocr Rev. 2011 Oct;32(5):670-93.

36. Iervasi G, Molinaro S, Landi P, Taddei MC, Galli E, Mariani F, et al. Association between increased mortality and mild thyroid dysfunction in cardiac patients. Arch Intern Med. 2007; 167(14):1526-1532.

Articles and any other material published in the JAFES represent the work of the author(s) and should not be construed to reflect the opinions of the Editors or the Publisher. Authors are required to accomplish, sign and submit scanned copies of the JAFES Declaration: that the article represents original material, that is not being considered for publication or has not been published or accepted for publication elsewhere. Consent forms, as appropriate, have been secured for the publication of information about patients; otherwise, authors declared that all means have been exhausted for securing such consent. The authors have signed disclosures that there are no financial or other relationships that might lead to a conflict of interest. All authors are required to submit Authorship Certifications that the manuscript has been read and approved by all authors, and that the requirements for authorship have been met by each author.

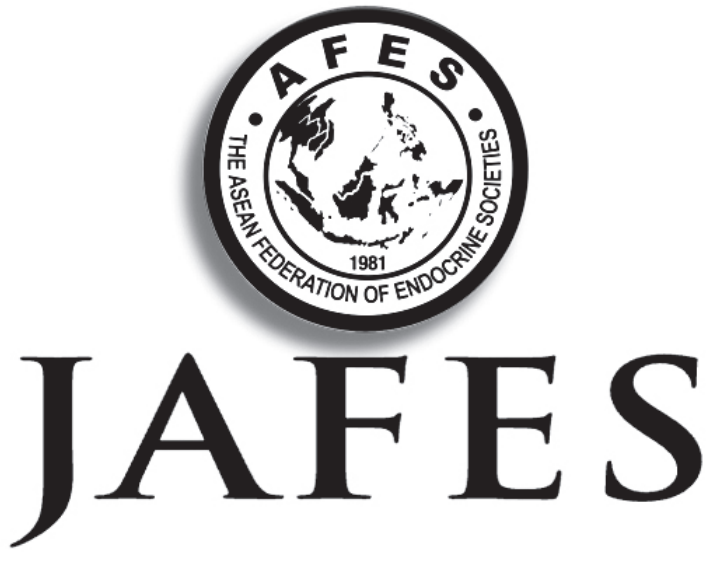

\section{A new venue for publishing your original articles. Visit www.ASEAN-endocrinejournal.org for Instructions to Authors.}

